\title{
The life cycle rebound effect of air-conditioner consumption in China
}

\author{
Jingru Liu ${ }^{\mathrm{a}, *}$, Xin Sun ${ }^{\mathrm{b}}$, Bin Lu ${ }^{\mathrm{a}}$, Yunkun Zhang ${ }^{\mathrm{c}}$, Rui Sun ${ }^{\mathrm{d}}$ \\ ${ }^{a}$ Research Center for Eco-Environmental Sciences, Chinese Academy of Sciences, 18 Shuangqing Road, Haidian District, Beijing 100085, China \\ ${ }^{\mathrm{b}}$ China Automotive Technology E Research Center, 68 East Xianfeng Road, Dongli District, Tianjin 300300, China \\ ${ }^{\mathrm{c}}$ University of East Anglia, Norwich Research Park, Norwich NR4 7TJ, UK \\ d Jilinhuancheng Rural Commercial Bank, 1888 Tianjin Road, Changyi District, Jilin, Jilin 132001, China
}

\section{H I G H L I G H T S}

- Develop a life cycle rebound effect model.

- Assess the life cycle rebound effect of Chinese room air conditioners.

- Conduct a questionnaire to assess the consumption behavior of Chinese room air conditioners.

- Rebound effect should be considered by energy policy makers.

\section{A R T I C L E I N F O}

\section{Article history:}

Received 15 September 2015

Received in revised form 11 November 2015

Accepted 26 November 2015

Available online 8 January 2016

\section{Keywords:}

Life cycle rebound effect

Carbon footprint

Room air conditioners

Sustainable consumption

\begin{abstract}
A B S T R A C T
Governments worldwide are attempting to reduce energy consumption and environmental pollution by confronting environmental problems and adopting more energy-efficient products. However, because of the rebound effect, energy-saving targets cannot always be fully achieved, and sometimes greater energy consumption is generated. Research on the rebound effect from the perspective of industrial ecology considers not only direct energy consumption but also its life cycle negative impacts on the environment with China's rapid economic development and simultaneously improving quality of life, the ownership of room air conditioners (RACs) has increased more than three hundred times, and air conditioners' energy consumption has increased one thousand times over the last twenty years. The Air Conditioner Energy Efficiency Standard is one of the most important measures in China for reducing the amount of energy consumed by RACs. This paper introduces a life cycle based method to estimate the rebound effect of Chinese RACs consumption. This model provides a product's life-cycle view to assess the rebound effect, considering the contribution of both producer and consumer. Based on the established life cycle rebound effect model, we compared urban household RAC consumption behaviour before and after the launch of the Air Conditioner Energy Efficiency Standard. A rebound effect in RAC consumption was found that there was a longer daily usage period in the household as air conditioner efficiency levels improved. The life cycle rebound effect of household air-conditioner consumption was calculated to be $67 \%$. The main conclusion obtained from this study is that policies and regulations should consider the rebound effect when encouraging households to alter their energy consumption patterns.
\end{abstract}

(c) 2015 Elsevier Ltd. All rights reserved.

\section{Introduction}

As the second leading energy sector in China by consumption, household energy usage has become the focus of substantial attention, and major efforts have been undertaken to generate improvements in household energy efficiency. The main reasons

\footnotetext{
* Corresponding author at: State Key Laboratory of Urban and Regional Ecology, Research Center for Eco-Environmental Sciences, Chinese Academy of Sciences, 18 Shuangqing Road, Haidian District, Beijing 100085, China.

E-mail address: liujingru@rcees.ac.cn (J. Liu).
}

for households' environmental impact involve energy consumption and greenhouse gas emission related to household heating and cooling [1].

The ownership of room air conditioners (RACs) in China increased from 0.34 units per hundred urban households in 1990 to 112.07 units in 2011, which was a higher growth rate than that of other household appliances, with an increase of more than 300 times in just twenty years. According to a report from the Ministry of Construction of China, summer-cooling energy consumption in China increased from 0.40 billion $\mathrm{kWh}$ in 1996 to 520.00 billion $\mathrm{kWh}$ in 2011 [2]. Electricity consumption by RACs is 
estimated to account for $30 \%$ of the peak summer load in some large and medium-sized cities [3].

To reduce the amount of energy consumed by RACs, China implemented the Air Conditioner Energy Efficiency Standard in 2008, which aimed at phasing out energy-inefficient RACs by incentivizing consumers to purchase highly energy-efficient RACs. However, advances in technology and improvements in energy efficiency - in addition to other relevant developments - also influence household consumption behaviour and paradoxically lead to increased energy consumption and greenhouse gas emissions $[4,5]$, which is a phenomenon known as the rebound effect.

\section{Literature review}

The notion of the rebound effect was first developed by Daniel Khazzoom in an estimation of energy savings based on mandated efficiency standards for household appliances in the USA [6] and has since been the focus of many studies [7-10]. Four types of rebound effects are identified in both the microeconomic and macroeconomic perspectives in the literature [9,11]: direct rebound effects, indirect rebound effects, economy-wide effects and transformational effects. Direct effects occur when improved energy efficiency decreases the effective price of an energy service and therefore leads to an increase in consumption of that service. This increase will offset the reduction of energy consumption caused by the advanced efficiency. Indirect rebound effects occur when a reduction in the effective cost of an energy service leads to an increase in energy demand for the production of other goods and services. Percentages are typically used to describe the rebound effect, and a backfire effect results when the rebound effect exceeds $100 \%$.

There are varieties of researches regarding to the direct rebound effect of household energy consumption in developed countries. The researches mainly focus on the household terminal energy use in the areas of space heating and cooling, transportation, hot water and lighting. Economic model and social investigation are adopted as the common methods. In the known cases, the sample size varies from dozens to ten thousands. The evidence shows that the direct rebound effect may be less than $30 \%$ in industrialized countries [12-14] and more than $30 \%$ in non-industrialized countries [15-18].

Household space heating and cooling are the most thoroughly studied area of direct rebound effects. Table 1 summarizes the main features and results in this research area.
In 2001, the concept of the rebound effect was introduced to industrial ecology [5].From the industrial ecology perspective, the rebound effect refers to a behavioural or other systemic response to a measure taken to reduce the life cycle environmental effects other than energy use - that offsets the benefit of the measure [28]. The research scope of the rebound effect of household consumption has been extended from energy consumption behaviour to energy consumption embodied in household products and services and related environmental impacts. The life cycle assessment method has been used in the area of sustainable consumption to identify which lifestyles are more sustainable and evaluate the effectiveness of sustainable consumption measures, including the role of the rebound effect in the environmental impact of household energy consumption $[29,30]$.

The rebound effect relevant to household RACs has drawn increasing concern over recent years. Studies have shown that the current measures and technologies promoting energy efficiency in China appear to be unable to control the increase in household energy consumption as the result of China's current rapid pace of economic development and the demand for a more comfortable lifestyle [31,32]. Some studies have demonstrated that the direct rebound effect of household energy consumption in China might be at least 30\%, and the indirect rebound effect is generally estimated to be much higher than the direct effect [33].

This paper first presents the definition of the life cycle environmental rebound effects of RACs and then describes a methodology to estimate the effects by comparing the carbon footprint of RACs before and after implementation of the Air Conditioner Energy Efficiency Standard in China. The RCEES Life Cycle Inventory was used to estimate the carbon footprint of RACs produced in 2008 and 2012 [34], and a questionnaire survey was conducted to analyse the changes in consumption behaviour given higher energy efficiency and lower energy costs.

\section{Methods and data}

\subsection{The life cycle rebound effect model for household room air conditioners}

The life cycle rebound effect of household RACs describes changes in the life cycle environmental performance of RACs as the result of the introduction of new energy-saving technologies and new energy efficiency standards. In this paper, the product's carbon footprint is chosen as the indicator of the life cycle environ-

Table 1

The main features and results of studies on the direct rebound effects of space heating and cooling.

\begin{tabular}{|c|c|c|c|c|}
\hline Author/year & Country & Rebound effect & Method & Sample size (year) \\
\hline \multicolumn{5}{|l|}{ Household space heating } \\
\hline Dubin et al. [19] & USA & $19-48 \%$ & Discrete-continuous & 252 \\
\hline Klein $[20,21]$ & USA & $40 \%$ & Simultaneous equations model & $\begin{array}{l}2157 \text { (1973, 1981, Cross- } \\
\text { section) }\end{array}$ \\
\hline Schwartz and Taylor [22] & USA & Long $1.4-3.4 \%$ & Questionnaire survey & $1188(1984-1985)$ \\
\hline Cuijpers [23] & Belgium & $31 \%$ & Questionnaire survey & $2075(1987-1988)$ \\
\hline Haas and Biermayr [13] & Austria & $20-30 \%$ & Time series analysis & $500(1970-1995)$ \\
\hline Nesbakken [24] & Norway & $\begin{array}{l}15-55 \% \text { (average } \\
21 \% \text { ) }\end{array}$ & Discrete- continuous & 1990 \\
\hline Guertin et al. [25] & Canada & Long $29-47 \%$ & Model for analysis of energy demand & 10,982 (1999, Cross-section) \\
\hline Gram-Hanssen et al. [26] & Denmark & $20 \%$ & Questionnaire survey & $665(2010)$ \\
\hline \multicolumn{5}{|l|}{ Household space cooling } \\
\hline Hausman [27] & USA & $\begin{array}{l}\text { Short } 4 \% \text {, Long } \\
26.5 \%\end{array}$ & $\begin{array}{l}\text { Individual behavioural model, price elasticity and discrete } \\
\text { choice models }\end{array}$ & 46 (1978, Cross-section) \\
\hline Dubin et al. [19] & USA & $1-26 \%$ & Discrete- continuous, engineering thermal load model & 214-396 (1981, Cross-section) \\
\hline Guertin et al. [25] & Canada & Long $34-38 \%$ & Model of residential energy demand & 10,982 (1999, Cross-section) \\
\hline Jin [17] & Korea & $57-70 \%$ & Nonlinear correlation direct estimation & $\begin{array}{l}\text { Two household (2002, Cross- } \\
\text { section) }\end{array}$ \\
\hline
\end{tabular}


mental impact. Correspondingly, the rebound effect of the carbon footprint (REC) can be expressed as the size of carbon footprint changes, as Eq. (1) shows, where the REC equals the expected reduction in environmental impact minus the actual reduction in impact, divided by the expected reduction.

$\mathrm{REC}=\frac{\left(\mathrm{C}_{0}-\mathrm{C}_{1}\right)-\left(\mathrm{C}_{0}-\mathrm{C}_{1}^{\prime}\right)}{\left(\mathrm{C}_{0}-\mathrm{C}_{1}\right)} \times 100 \%$

- REC: the life cycle rebound effect of RACs, expressed by the change in the carbon footprint;

- $\mathrm{C}_{0}$ : the carbon footprint of RACs without energy-saving technology;

- $\mathrm{C}_{1}$ : the carbon footprint of RACs with energy-saving technology and considering efficiency substitution effects;

- $\mathrm{C}_{1}^{\prime}$ : the carbon footprint of RACs with energy-saving technology and considering both efficiency substitution effects and the carbon footprint caused by changes in consumer behaviour;

- $\mathrm{C}_{0}-\mathrm{C}_{1}$ : expected carbon footprint caused by energy-saving technology;

- $\mathrm{C}_{0}-\mathrm{C}_{1}^{\prime}$ : actual reduction of the carbon footprint.

When building the carbon footprint rebound model for RACs, this study took the following factors into account:

(1) The environmental parameter: this factor can be expressed by the carbon footprint of RACs (C), considering the entire life cycle of RACs from material extraction, manufacturing, distribution, usage, to end-of-life;

(2) The consumption behaviour parameter: this factor can be expressed by setting the temperature of $\operatorname{RACs}(t)$, hours of usage $(h)$, and ownership of air conditioners $(n)$;

(3) The technological parameter: this factor can be expressed by the operating power $(p)$ and the carbon footprint of electricity production $(\xi)$.

The carbon footprint rebound effect (REC) is a function of all the above-mentioned variables, as shown in Eq. (2):

$\mathrm{REC}=f(c, t, h, n, p, \xi, \ldots)$

To highlight the effects of consumption behaviour, the carbon footprint can be calculated as follows:

$\mathrm{C}=\mathrm{MC}+\mathrm{DC}+\mathrm{UC}+\mathrm{EC}=\mathrm{MDUC}+\xi p t h$

- C: carbon footprint of RACs;

- MDUC: the sum of the carbon footprint generated through RAC manufacturing (MC), distribution (DC), usage (UC) and end-oflife stage (EC);

- $\xi$ pth: the sum of the carbon footprint generated in the usage stage of RACs, as determined by the carbon footprint of electricity, hours of usage, operating power and the temperature setting.

Then, $C_{0}, C_{1}$ and $C_{1}^{\prime}$ can be expressed as follows:

$\mathrm{C}_{0}=\mathrm{MDUC}_{0}+\xi_{0} P_{0} t_{0}$

$\mathrm{C}_{1}=\mathrm{MDUC}_{1}+\xi_{1} P_{1} t_{0}$

$\mathrm{C}_{1}^{\prime}=\mathrm{MDUC}_{1}+\xi_{1} P_{1} t_{1}$

Substituting (4)-(6) into Eq. (1), a new expression for the carbon footprint rebound effect can be obtained:

$\mathrm{REC}=\frac{\xi_{1} p_{1}\left(t_{1}-t_{0}\right)}{\mathrm{MDUC}_{0}-\mathrm{MDUC}_{1}+\left(\xi_{0} P_{0}-\xi_{1} P_{1}\right) t_{0}} \times 100 \%$ where

- $\mathrm{MDUC}_{0}$ represents the carbon footprint of a low energy efficiency RAC generated through the material extraction, manufacturing and end-of-life stages:

- MDUC $_{1}$ represents the carbon footprint of an energy-saving RAC generated in the material extraction, manufacturing and endof-life stages;

- $\xi_{0}$ represents the electricity-generating-related carbon footprint factor of a low energy efficiency RAC;

- $\xi_{1}$ represents the electricity-generating-related carbon footprint factor of an energy-saving RAC;

- $P_{0}$ represents the operating power of the low energy efficiency RAC;

- $P_{1}$ represents the operating power of the energy-saving RAC;

- $t_{0}$ represents the usage hours of the low energy efficiency RAC;

- $t_{1}$ represents the usage hours of the energy-saving RAC.

\subsection{The survey on household air conditioner consumption behaviour}

\subsubsection{Household questionnaire and sampling size}

A questionnaire was developed to assess the household consumption behaviour of RACs. The questionnaire contained three sections: (1) the basic family situation; (2) the ownership of household RACs and their related parameters; and (3) the usage behaviour of household RACs.

The following sample size formula was adopted to ensure that the sample represented households nationwide:

$n=\frac{\left(z_{\alpha / 2}\right)^{2} \cdot \pi(1-\pi)}{E^{2}}$

in which $n$ is the sample size, $Z_{\alpha / 2}$ is the critical value at a $95 \%$ confidence level (which equals 1.96), $\pi$ is the percentage of households using RACs in China ( 0.5 used for the necessary sample size), and $E=0.05$ (which represents the significance level).

The calculation result of the formula indicates that the sample should include at least 385 objectives. Considering the response rate, 400 questionnaires were issued.

\subsubsection{Survey mode}

The feasibility and validity of the survey were verified by a test of 50 households before the formal questionnaire was issued. A total of 400 questionnaires were issued; of these, 300 questionnaires were distributed online using a professional survey website. The survey targets were selected randomly, and the questionnaire links were sent to these targets. Any invalid questionnaires were identified and rejected through a specific website setting to guarantee the response rate and survey quality. The other 100 questionnaires were given through face-to-face interviews by well-trained interviewers in Beijing. Ultimately, the survey response rate reached more than $85 \%$.

To confirm the reliability of the collected data, 30 respondents were selected randomly and telephone interviews were conducted after $48 \mathrm{~h}$ involving the same content as the original survey. The results of the two surveys were analysed by hypothesis testing. There was no significant difference between the mean values of these two surveys. The results of a t-test were not significant at the level of $\alpha=0.05$, indicating that the survey is credible.

\subsubsection{Survey results}

The data analysed in this section derive from 385 valid questionnaire surveys. Only one-fourth $(25.43 \%$ of the total) of the respondents own three or more RAC units. More than $74 \%$ of the households own one or two RAC units. The average monthly electricity consumption per household for cooling service on hot days is displayed in Fig. 1, which shows that most households 
consume 51-200 kW h electricity per month, whereas the sum of households using fewer than $50 \mathrm{kWh}$ and more than $300 \mathrm{kWh}$ per month account for $12.29 \%$ of the total samples.

The Energy Efficiency Label measure was launched in China in 2005. There are five energy efficiency grades for RACs based on the efficiency ratio. Level 1 means that the energy efficiency of the RAC has reached an advanced international level. Level 5 is the minimum requirement for an RAC to access the market. Fig. 2 shows the distribution of different energy efficiency levels of the RACs used in this research. Families with energy-saving RACs (Energy Efficiency Levels 1 and 2) and families with low energy efficiency RACs (Levels 4 and 5) account for $43.14 \%$ and $14.29 \%$ of the entire sample, respectively. RACs without an Energy Efficiency Label (the group of others in Fig. 2) account for $23.14 \%$ of the sample, and these were bought before 2005.

An air conditioner is an appliance designed to maintain indoor temperature at a given level. According to the survey, $74.57 \%$ of households choose to set the temperature at $24-28^{\circ} \mathrm{C}$ on hot days. To promote energy conservation, the State Council of China issued a notice in 2007 that claims that the temperature in public spaces should be set above $26^{\circ} \mathrm{C}$. Although there is no requirement for household air temperature control, most families set a temperature close to $26^{\circ} \mathrm{C}$. However, more than $22 \%$ of families still set their temperature below $24{ }^{\circ} \mathrm{C}$ (Fig. 3), which means that there is potential for household energy saving.

Fig. 4 shows that more than $75 \%$ of households use RACs for 30-60 or 60-90 days for cooling.

Fig. 5 shows that RACs were used more frequently at night during the hot seasons than during the day. During the day, $42.00 \%$ of the surveyed families used RACs for less than $3 \mathrm{~h}$ and $28.57 \%$ for more than five hours. At night, $30.29 \%$ of families used RACs for less than $3 \mathrm{~h}$ and $47.14 \%$ used RACs for more than $5 \mathrm{~h}$.

\subsubsection{Test of the rebound effect}

It could be assumed that households might use more energy by setting the temperature lower and using the RACs longer because the energy efficiency of RACs decreases a household's operating cost. To prove the existence of a rebound effect in household RAC consumption, a one-way analysis of variance is adopted to test the hypothesis that the energy efficiency level will influence people's decisions regarding temperature setting and usage hours for RACs.

Before applying a one-way analysis of variance, some fundamental assumptions must be made. The observations in this research can be regarded as a simple random sample of a homoscedastic population with a normal distribution. In addition, this study assumes that households with different energy efficiency

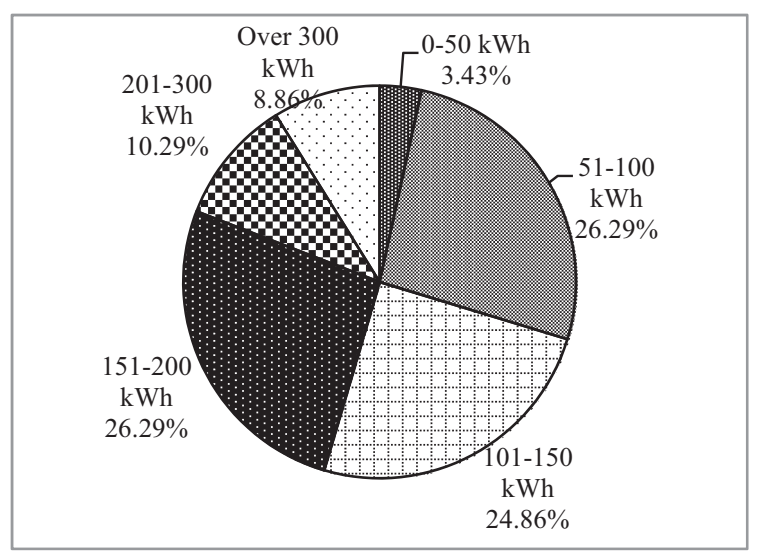

Fig. 1. Average household electricity consumption per month during the hot season.

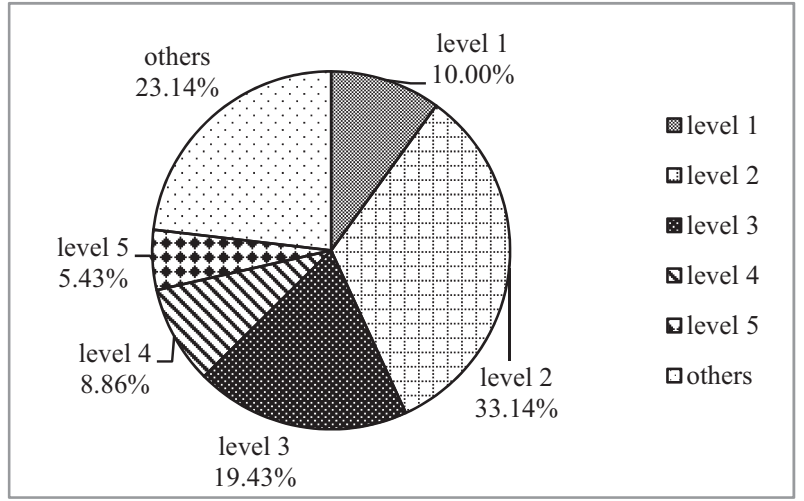

Fig. 2. Survey statistics on air conditioner energy efficiency levels.

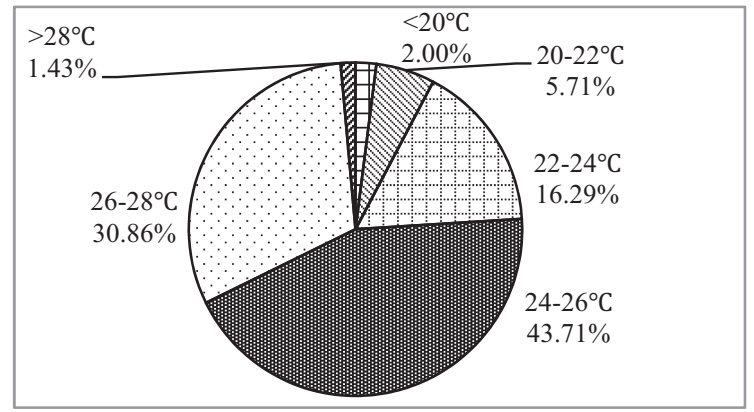

Fig. 3. Air temperature settings during the cooling seasons.

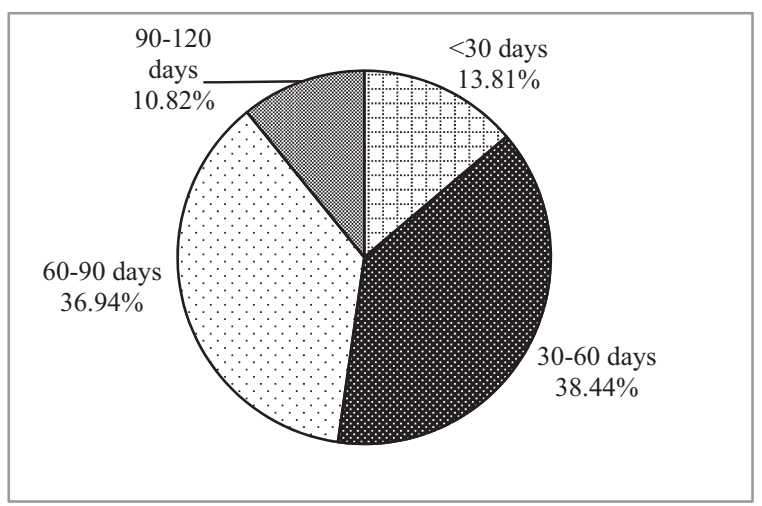

Fig. 4. Number of days per year on which air conditioners are used for cooling.

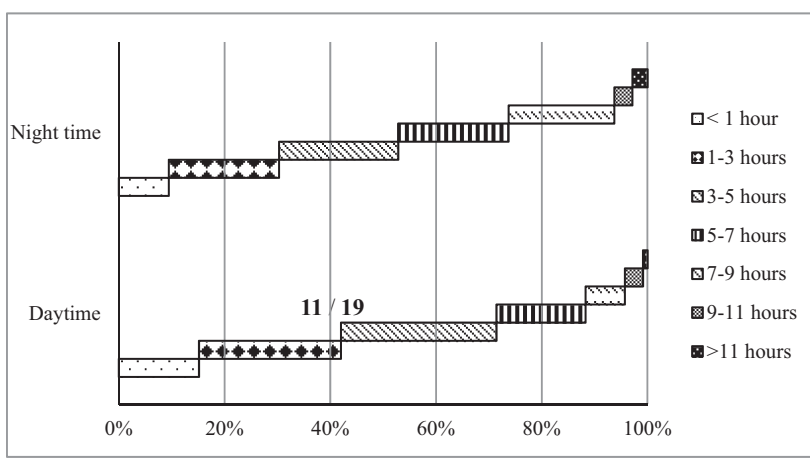

Fig. 5. Average air conditioner usage by time per day during the cooling seasons. 
Table 2

Analysis of how the "Energy Efficiency Level" influences the "Temperature Setting".

\begin{tabular}{|c|c|c|c|c|c|c|}
\hline Sources of deviation & Squared sum & Freedom degree & Mean square & $F$ & $P$ & $F$ threshold \\
\hline Inter-block (influence factor) & 26.321 & 5 & 5.264 & 1.408 & 0.221 & 2.240 \\
\hline Intra-class (deviation) & 1285.679 & 344 & 3.737 & & & \\
\hline Total & 1312 & 349 & & & & \\
\hline
\end{tabular}

Table 3

Analysis of how the "Energy Efficiency Level" influences "Usage Hours".

\begin{tabular}{|c|c|c|c|c|c|c|}
\hline Sources of deviation & Quadratic sum & $\mathrm{d} f$ & MS & $F$ & $P$ & $F$ threshold \\
\hline Inter-block (influence factor) & 1202.345 & 5 & 240.469 & 13.18505 & 0.0000 & 2.240228 \\
\hline Intra-class (deviation) & 6273.872 & 344 & 18.238 & & & \\
\hline Sum & 7476.217 & 349 & & & & \\
\hline
\end{tabular}

level RACs are mutually independent in their temperature settings and usage time. Microsoft Excel is used to obtain the one-way analysis of variance results showing how the "Energy Efficiency Level" influences the "Temperature Setting" and "Usage Hours". The significance test conducted here is on the basis of F-test, revealing whether between-group variance significantly influences total variance.

Table 2 provides the results of the analysis as to whether the "Energy Efficiency Level" influences the "Temperature Setting" and shows that $\mathrm{F}=1.408479<\mathrm{F}$ Threshold $=2.240228$ and $P=0.220523>0.05$. The result of the F-test is not significant. Therefore, the null hypothesis should not be rejected. In other words, the energy efficiency level does not have a significant impact on the temperature setting.

Table 3 shows the results for how the "Energy Efficiency Level" influences "Usage Hours". The result of the F-test are highly significant, as $\mathrm{F}=13.18505>\mathrm{F}$, Threshold $=2.240228$ and $\mathrm{P}=0.0000<0.05$. Therefore, the null hypothesis should be rejected, which means that the energy efficiency level does have a significant impact on usage hours.

The above analysis shows that the RACs' energy efficiency level has a significant impact on usage hours but not on the temperature setting. To clarify whether the influence of the energy efficiency level on usage hours is positive, a further analysis of the results is conducted. SPSS is used to investigate the detailed correlation between "Energy Efficiency Level" and "Usage Hours". In this study, the Spearman correlation analysis method is adopted to test the significance of the variations across energy efficiency levels, and the Kendall correlation analysis was adopted to determine the matching attributes (Table 4).

Table 3 shows that the Spearman correlation coefficient is -0.341 and the Kendall correlation coefficient is -0.266 ; both coefficients are negative and significant at the 0.01 level. These results prove that there is a significant negative correlation between the "Energy Efficiency Level" and "Usage Hours". As noted above, the higher the energy efficiency level is, the lower the energy efficiency. Hence, the higher a household RAC's energy efficiency is, the longer the RAC will be used. Therefore, the rebound effect does exist for household RAC consumption.

Table 4

The correlation between energy efficiency level and usage hours.

\begin{tabular}{llll}
\hline & Correlation coefficient & Significance & $\mathrm{N}$ \\
\hline Spearman correlation analysis & $-0.341^{* *}$ & 0.000 & 350 \\
Kendall correlation analysis & $-0.266^{* *}$ & 0.000 & 350 \\
\hline
\end{tabular}

${ }^{* *}$ Indicates that the significance level equals 0.01 .

\section{Results}

According to the survey, the split type of RAC is the most common in Chinese households. The split RAC system consists of two units (one indoor and one outdoor unit) connected only by a pipe that transfers the refrigerant. The indoor unit includes the evaporator and a fan, whereas the outdoor unit contains a compressor and a condenser. By using SimaPro software version 7.1 with the RCEES 2008 and RCEES 2012 databases, this paper analysed the carbon footprint of the typical Chinese household RACs produced in 2008 and 2012 separately based on the international standard of the PAS 2050.

The environmental impacts of the production stage depend mainly on the materials out of which the product is made. This information was provided by manufactures. Table 5 presents the main material components of the reference cases (see Table 5).

The RCEES database developed by previous researchers (Yang, 2004; Sun, 2014) provides the values of $\xi_{0}, \xi_{1}$, (MDUC M $_{0}-$ MDUC $\left._{1}\right)$. $\xi_{0}$ is $0.54 \mathrm{kgCO}_{2}$-eq/MJ (RCEES 2008) and $\xi_{1}$ is $0.27 \mathrm{kgCO}_{2}$-eq/MJ (RCEES 2012), that is, $\xi_{0}=2 \xi_{1}$. The carbon footprint generated during the usage stage accounts for $90 \%$ of the total carbon footprint during the life cycle of an air conditioner, whereas the other three stages combined-namely, MDUC-only account for $10 \%$. According to the survey, the values of these parameters can be obtained: $P_{0} \approx 1.00 \mathrm{~kW} / \mathrm{h}, \quad P_{1} \approx 0.50 \mathrm{~kW} / \mathrm{h}, \quad t_{0}=3.20 \mathrm{~h}, \quad t_{1}=10.10 \mathrm{~h}, \quad$ so $P_{0} \approx 2 P_{1}$ and $t_{1}=3 t_{0}$.

Table 5

Main components and data for the materials in household air-conditioning units.

\begin{tabular}{llll}
\hline Material & Weight $(\mathrm{kg})$ & $\begin{array}{l}\text { Carbon footprint } \\
\left(\mathrm{kgCO}_{2} \text {-eq }\right)\end{array}$ & LCI data source \\
\hline $\begin{array}{l}\text { Energy-saving RAC } \\
\text { Iron }\end{array}$ & 2.46 & 8.96 & RCEES 2012 \\
Steel & 13.96 & 102 & RCEES 2012 \\
Brass & 0.56 & 1.28 & RCEES 2012 \\
Copper & 9.88 & 93.20 & RCEES 2012 \\
Aluminium & 2.88 & 5.84 & RCEES 2012 \\
ABS & 6.74 & 124.00 & RCEES 2012 \\
R410a & 0.90 & 156.00 & RCEES 2012 \\
Epoxy resin & 1.28 & 8.60 & ECoinvent 2.1 \\
Total & $\mathbf{3 9 . 2 8}$ & $\mathbf{4 9 9 . 8 8}$ & \\
Non-energy-saving $R A C$ & & & RCEES 2008 \\
Steel & 23.41 & 171.00 & RCEES 2008 \\
Copper & 9.44 & 89.00 & RCEES 2008 \\
Aluminium & 4.39 & 8.91 & RCEES 2008 \\
ABS & 8.93 & 165.00 & ECoinvent 2.1 \\
PWB & 1.58 & 83.40 & \\
Total & $\mathbf{5 1 . 0 0}$ & $\mathbf{5 1 7 . 3 1}$ & \\
\hline
\end{tabular}


Substituting the above parameters into Eq. (7) provides:

$$
\mathrm{REC}=\frac{\xi_{1} P_{1}\left(3 t_{0}-t_{0}\right)}{(517.31-499.88)+\left(4 \xi_{1} P_{1}-\xi_{1} P_{1}\right) t_{0}} \times 100 \%=67 \%
$$

This result shows that after the launch of the Air Conditioner Energy Efficiency Standard, 67\% of the expected reduction in the carbon footprint of household RACs has been offset by the rebound effect. Therefore, the actual reduction achieved by using energyefficient RACs (compared with using non-energy-efficient RACs) is just $33 \%$.

\section{Implications}

China is now the world's largest consumer of RACs, and its consumption will continue to rise along with its rapid economic growth and improvements in quality of life. RACs are also considered important potential contributors to energy reduction because they contribute $50 \%$ to total home appliance energy consumption. The life cycle rebound effect of RAC consumption was estimated in this paper. The developed life cycle rebound effect model finds that the rebound effect of Chinese urban RACs is approximately $67 \%$. In other words, $67 \%$ of the expected reduction in the carbon footprint of household RACs is offset by the rebound effect. It can be inferred that the rebound effect is ubiquitous in household energy efficiency of China.

China is the largest developing country in the world, but due to its limited natural resources, huge population, and lack of advanced technologies, it is under growing pressure to meet its citizens' desire for a better quality of life. Growing environmental degradation in China will be related to the residential consumption that accompanies increases in income and living standards. Although the energy intensity of industrial economies is steadily declining, the absolute energy consumption and associated carbon emissions attributable to households continues to rise [34-39]. Households are expected to play a pivotal role in reducing future greenhouse gas emissions. Policies and regulations should encourage households to contribute to reduce greenhouse gas emissions $[40,41]$. When assessing the potential benefits of energy efficiency technologies in the household sector of China, the rebound effect should be taken into account.

\section{Conclusions}

This study calculated a life cycle rebound effect model for RACs in China and offers some policy suggestions to reduce the rebound effect. The main contribution of this paper is the life cycle rebound effect model, because this model provides a product's life-cycle view to assess the rebound effect, considering the contribution of both producer and consumer, this is a more scientific and systematic approach to discuss the effectiveness of a new energy policy.

The main conclusions are as follows.

First, this study proposed a definition of the life cycle environmental rebound effects of household RACs and established a life cycle rebound effect model for RACs. The methodology to estimate the effect compares the carbon footprint of RACs before and after implementation of the Air Conditioner Energy Efficiency Standard in China.

Second, by investigating the use and maintenance of 400 households that were using air conditioners, we found that there was a longer daily usage period in the household as air conditioner efficiency levels improved. This result confirmed that there was a rebound effect in RAC consumption.

Third, this paper analysed the carbon footprint of typical Chinese RACs produced in 2008 and 2012 separately based on the international the PAS 2050 standard. SimaPro software version
7.1 with database RCEES 2012 and Ecoinvent 2.1 was used. With the information provided by the manufacturers, this study found that the carbon footprint of an RAC in the production stage mainly depends on the raw materials.

Finally, with the application of the life cycle rebound effect model for RACs, we calculated that the life cycle rebound effect for household air-conditioner consumption is $67 \%$.

This paper highlights the importance of taking the rebound effect into consideration when developing energy policies. Control strategies and policies are required based on a scientific understanding of consumers' consumption patterns. Awareness and information campaigns combined with economic instruments should be adopted as incentives and encouragement to promote sustainable consumption patterns; otherwise, the effectiveness of energy efficiency policies in households will be reduced.

The quantification of rebound effects is difficult because of the uncertain causal relationships of money saving and respending. Therefore, a relative simple rebound effect model was adopted in this paper, only considering the critical factors, such as the carbon footprint of household RACs, the progress in cleaner electricity generation, technological advances in RACs and usage behaviour of consumers. In future research, other parameters such as household income and expenditure, the number of family members and the effect of climate change can be added to the model.

\section{Acknowledgements}

This study is supported by the National Natural Science Foundation of China (No. 71033005) and the Strategic Priority Research Program of Chinese Academy of Sciences (No. XDA05140105, XDA05140200).

\section{References}

[1] Freire-González J. Methods to empirically estimate direct and indirect rebound effect of energy-saving technological changes in households. Ecol Model 2011;223:32-40.

[2] Center QBER. 2013 Annual Report on China Building Energy Efficiency. Beijing: China Architecture \& Building Press; 2013.

[3] Yu H, Tang B-J, Yuan X-C, Wang S, Wei Y-M. How do the appliance energy standards work in China? Evidence from room air conditioners. Energy Build 2015;86:833-40.

[4] Brännlund R, Ghalwash T, Nordström J. Increased energy efficiency and the rebound effect: effects on consumption and emissions. Energy Econ 2007:29:1-17.

[5] Binswanger M. Technological progress and sustainable development: what about the rebound effect? Ecol Econ 2001;36:119-32.

[6] Khazzoom JD. Economic implications of mandated efficiency in standards for household appliances. Energy J 1980;1:21-40.

[7] Brookes LG. Energy policy, the energy price fallacy and the role of nuclear energy in the UK. Energy Policy 1978;6:94-106.

[8] Barker T, Ekins P, Foxon T. The macro-economic rebound effect and the UK economy. Energy Policy 2007;35:4935-46.

[9] Greening LA, Greene DL, Difiglio C. Energy efficiency and consumption - the rebound effect - a survey. Energy Policy 2000:28:389-401.

[10] Gillingham K, Kotchen MJ, Rapson DS, Wagner G. Energy policy: the rebound effect is overplayed. Nature 2013;493:475-6.

[11] Sorrell S, Dimitropoulos J. The rebound effect: microeconomic definitions, limitations and extensions. Ecol Econ 2008;65:636-49.

[12] Haas R, Auer H, Biermayr P. The impact of consumer behavior on residential energy demand for space heating. Energy Build 1998;27:195-205.

[13] Haas R, Biermayr P. The rebound effect for space heating empirical evidence from Austria. Energy Policy 2000;28:403-10.

[14] Sorrell S, Dimitropoulos J, Sommerville M. Empirical estimates of the direct rebound effect: a review. Energy Policy 2009;37:1356-71.

[15] Roy J. The rebound effect: some empirical evidence from India. Energy Policy 2000;28:433-8.

[16] Spalding-Fecher, Clark A, Davis M, Simmonds G. The economics of energy efficiency for the poor-a South African case study. Energy 2002:27:1099-117.

[17] Jin S-H. The effectiveness of energy efficiency improvement in a developing country: rebound effect of residential electricity use in South Korea. Energy Policy 2007;35:5622-9.

[18] Wang Zhaohua, Lu Milin, Wang Jian Cai. Direct rebound effect on urban residential electricity use: an empirical study in China. Renew Sustain Energy Rev 2014;30:124-32 
[19] Dubin JA, Miedema AK, Chandran RV. Price effects of energy-efficient technologiesa study of residential demand for heating and cooling. Rand J Econ 1986;17:310-25.

[20] Klein YL. Residential energy conservation choices of poor households during a period of rising fuel prices. Resources Energy 1987;9:363-78.

[21] Klein YL. An econometric model of the joint production and consumption of residential space heat. South Econ J 1987;55:351-9.

[22] Schwartz PM, Taylor TN. Cold hands, warm hearth?: climate, net takeback, and household comfort. Energy J 1995;16.

[23] Cuijpers C. An empirical investigation into the economics of house heating. In: 50 PERPN, editor. Centrum Voor Economische Studien. Leuven, Belgium; 1996.

[24] Nesbakken R. Energy consumption for space heating: a discrete-continuous approach. Scand J Econ 2001;103:165-84.

[25] Guertin C, Kumbhakar S, Duraiappah A. Determining demand for energy services: investigating income-driven behaviours. Canada: International Institute for Sustainable Development; 2003.

[26] Gram-Hanssen K, Christensen TH, Petersen PE. Air-to-air heat pumps in reallife use: are potential savings achieved or are they transformed into increased comfort? Energy Build 2012;53:64-73.

[27] Hausman JA. Individual discount rates and the purchase and utilization of energy-using durables. Bell J Econ 1979;10:33-54.

[28] Hertwich EG. Consumption and the rebound effect: an industrial ecology perspective. I Ind Ecol 2005:9:85-98.

[29] Spielmann M, de Haan P, Scholz RW. Environmental rebound effects of highspeed transport technologies: a case study of climate change rebound effects of a future underground maglev train system. J Cleaner Prod 2008; 16:1388-98.

[30] Ornetzeder M, Hertwich EG, Hubacek K, Korytarova K, Haas W. The environmental effect of car-free housing: a case in Vienna. Ecol Econ 2008; 65:516-30.
[31] Nie H, Kemp R. Index decomposition analysis of residential energy consumption in China: 2002-2010. Appl Energy 2014;121:10-9.

[32] Yuan B, Ren S, Chen X. The effects of urbanization, consumption ratio and consumption structure on residential indirect $\mathrm{CO}_{2}$ emissions in China: a regional comparative analysis. Appl Energy 2015;140:94-106.

[33] Ouyang J, Long E, Hokao K. Rebound effect in Chinese household energy efficiency and solution for mitigating it. Energy 2010;35:5269-76.

[34] Xu X, Zhao T, Liu N, Kang J. Changes of energy-related GHG emissions in China: an empirical analysis from sectoral perspective. Appl Energy 2014; 132:298-307.

[35] Yang Haiyan ZM, Liu Jiangwei, Yuan Donghai. Practical insights and illustrative examples on Sustainable Consumption Case Studies from China. School of Environment and Energy Engineering, Beijing Institute of Civil Engineering and Architecture; 2012.

[36] Tseng M-L, Chiu SF, Tan RR, Siriban-Manalang AB. Sustainable consumption and production for Asia: sustainability through green design and practice. Cleaner Prod 2013;40:1-5.

[37] Dietz T. Understanding environmentally significant consumption. Proc Nat Acad Sci USA 2014:111:5067-8.

[38] Liu J, Wang R, Yang J, Shi Y. The relationship between consumption and production system and its implications for sustainable development of China. Ecol Complex 2010;7:212-6.

[39] Li K, Lin B. Heterogeneity in rebound effects: estimated results and impact of China's fossil-fuel subsidies. Appl Energy 2015;149:148-60.

[40] Lin B, Liu X. Electricity tariff reform and rebound effect of residential electricity consumption in China. Energy 2013:59:240-7.

[41] Lin B, Liu H. A study on the energy rebound effect of China's residential building energy efficiency. Energy Build 2015;86:608-18. 